Pensamiento Crítico N. ${ }^{\circ} 13$, pp. 7-21

\title{
Migración de peruanos a Japón
}

\author{
Carlos Aquino Rodríguez ${ }^{1}$ \\ carloskobe2005@yahoo.com
}

\section{RESUMEN}

El artículo describe el estado de la migración de peruanos a Japón. El número de peruanos en Japón disminuyó un poco en el 2009 por la crisis económica en ese país. Se describe primero brevemente el porqué los peruanos emigraron, específicamente a Japón. Segundo se ve las razones de por qué algunos se regresaron en el 2009, en tercer lugar se observa el estado de las remesas desde ese país y la situación actual de los peruanos allá, y finalmente se da unas conclusiones.

Palabras clave: Migración, peruanos en Japón, remesas.

\begin{abstract}
The article describes the situation of Peruvians migrants in Japan. Their number decreased in 2009 because the Japanese economy experimented a recession. First the reasons behind the departure of Peruvian to Japan are addressed, second why some of them came back to Peru is seen, and third the amount of remittances from that country is analyzed, and lastly some conclusions are given.
\end{abstract}

Keywords: Migration, Peruvians in Japan, Remittances.

1 Carlos Aquino Rodríguez es profesor de Economía de la UNMSM. Especialista en Economía Asiática, hizo su maestría y doctorado en Japón. Tiene diversas publicaciones sobre el tema. 


\section{Pensamiento Crítico N. 13}

\section{Introducción}

La migración de personas, el movimiento internacional del factor trabajo, es cada vez más creciente en el mundo. El Perú no es ajeno a ello. Según algunos cálculos, más del $10 \%$ de los peruanos están fuera del país, y muchos de ellos se han ido en los últimos 20 años $^{2}$.

En el presente artículo se analiza el fenómeno de la migración de peruanos a Japón, un país que tradicionalmente no ha admitido trabajadores extranjeros, y lo empezó a hacer de forma limitada desde la segunda mitad de la década de 1980. Se ve en más detalle la evolución de los emigrantes peruanos en el país nipón entre el 2008 y 2009, cuando ese país se enfrentó contra una recesión económica que ha visto disminuir el número de extranjeros y peruanos en ese país. Primero se verá las razones de la migración de peruanos a Japón; segundo, el porque de la disminución en su número en el 2009, tercero, la situación actual de ellos, y cuarto se dará algunas conclusiones.

\section{Razones de la migración de peruanos a Japón}

La migración de personas ocurre, según la teoría económica, cuando estos salen en busca de mejores horizontes económicos, de mejores salarios. Los países que los acogen experimentan escasez de mano de obra o sus ciudadanos no quieren trabajar en determinadas actividades.

En el caso de los peruanos que se fueron hacia Japón por las causas arriba mencionadas, aconteció por un lado que el Perú en la década de 1980 experimentó su llamada década pérdida de bajo o nulo crecimiento económico e hiperinflación (aunada a la violencia terrorista que se inició en esa década), que obligó a los peruanos a empezar a salir al exterior; por otro lado, Japón empezó a experimentar una escasez de mano de obra por esos años.

En el caso de Japón, desde la segunda mitad de 1980 su moneda empezó a revaluarse pasando de un valor promedio de 250 yenes por dólar en 1985 a 120 yenes

2 Según Aníbal Sánchez Aguilar en su libro "Caso Perú: Cambios Demográficos y Movilidad Laboral en la Región Asia Pacífico 2007-2008”, página 33, se calcula que 3 millones 129 mil personas se fueron del país y no regresaron y, de ese número, en el periodo 1990-2008 se fueron y no retornaron 2 millones 13 mil 90. 


\section{Carlos Alberto Aquino Rodríguez}

por dólar en 1989 hasta llegar a un valor de 90 yenes por dólar en 1995. Así el trabajar en Japón se volvió atractivo pues el sueldo en dólares prácticamente se triplicó entre 1985 y 1995.

Según el Gráfico 1 entre 1990 y el 2008 unos 2013800 peruanos emigraron al extranjero, y de esos solo una pequeña parte fue a Japón, 74 484, o un 3,7\% del total (cifra que como se vera en el acápite II no coincide con las cifras japonesas).

Gráfico 1: Emigración internacional de peruanos entre 1990-2008.

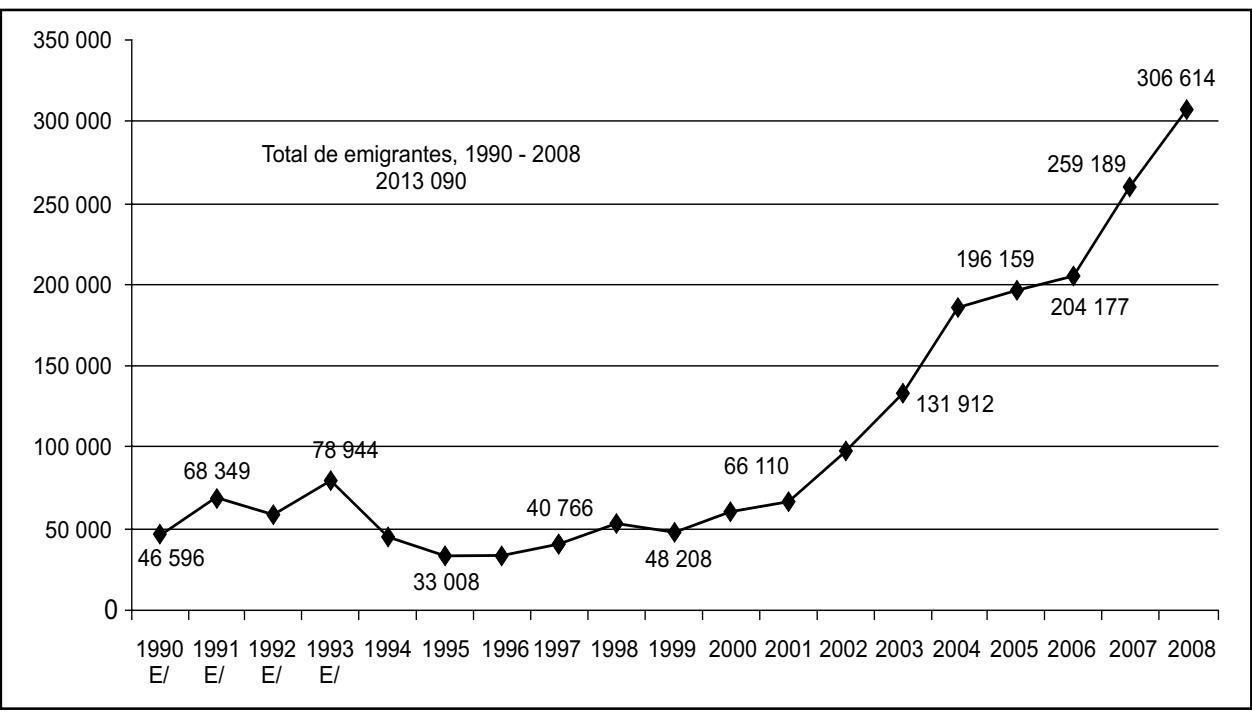

Fuente: Gráfico 1, OIM-DIGEMIN-INEI: "Perú: Estadísticas de la Migración Internacional de Peruanos, 1990 2008".

\section{La disminución en el número de peruanos en Japón en el 2009}

En el 2009 el número de peruanos en Japón se redujo por primera vez desde que empezó la masiva migración de compatriotas a ese país desde fines de la década de 1980. Así, a fines de diciembre del 2009 habían 57464 peruanos en Japón, un 3,9\% menos de los que habían un año antes, esto es 59723 (mientras tanto, el número de brasileños en el país nipón disminuyó un $16.8 \%$ de 312582 a 267456 en ese mismo 


\section{Pensamiento Crítico N. 13}

lapso) $)^{3}$. Esa reducción también se dio en el número total de extranjeros que paso de 2217121 a fines del 2008 a 2186121 a fines del 2009 y se produjo por la crisis económica internacional que afecto fuertemente a Japón. Ver Cuadro 1. La economía japonesa decreció $-1,2 \%$ en el 2008 y -5,2\% en el 2009.

Cuadro 1. Número de extranjeros en Japón, 2008 y 2009.

\begin{tabular}{|l|l|r|r|c|}
\hline & País & $\mathbf{2 0 0 9}$ & $\mathbf{2 0 0 8}$ & $\mathbf{~ \% ~}$ \\
\hline 1 & China & 680518 & 655377 & $+3,8$ \\
\hline 2 & Corea & 578945 & 589239 & $\mathbf{- 1 , 8}$ \\
\hline 3 & Brasil & 267456 & 312582 & $\mathbf{- 1 6 , 8}$ \\
\hline 4 & Filipinas & 211716 & 210617 & $+0,5$ \\
\hline 5 & Perú & 57464 & 59723 & $\mathbf{- 3 , 9}$ \\
\hline 6 & Otros & 390022 & 389583 & $+0,1$ \\
\hline & Total & 2186121 & 2217121 & $\mathbf{- 1 , 4}$ \\
\hline
\end{tabular}

Fuente: Noticias Nippon: "Disminuye el número de extranjeros residentes legalmente en el Japón", http://noticiasnippon.com/2010/07/07/disminuye-el-número-de-extranjeros-residentes-en-el-japon/

El número de peruanos en el país nipón empezó a subir desde 553 en 1986 a 4121 en 1989, y la cifra se disparo cuando en 1990 se cambia la ley para permitir que peruanos de ascendencia japonesa (nikkei) trabajen en Japón en oficios intensivos y en mano de obra. Ver Gráfico 2.

Como se mencionó Japón había empezado a experimentar escasez de mano de obra y necesito de la presencia de trabajadores extranjeros. Por otro lado, el Perú no ofrecía empleo suficiente a su población y muchos empezaron a emigrar. Un aliciente adicional para ir a Japón fue la apreciación de su moneda, el yen, que empieza en 1985 y así el sueldo que se ganaba en Japón al cambiarlo en dólares era bastante atractivo. El yen se aprecia de un valor promedio de 250 yenes por dólar en 1985 a 120 yenes por dólar en 1989 y llega a 90 yenes por dólar en 1995. Actualmente, diciembre del 2010, el tipo de cambio esta en alrededor de 83 yenes por dólar (con el mismo número de yenes se compra tres veces más dólares ahora que en 1985).

3 Ver Noticias Nippon: "Disminuye el número de extranjeros residentes legalmente en el Japón", http:// noticiasnippon.com/2010/07/07/disminuye-el-número-de-extranjeros-residentes-en-el-japon/ 


\section{Carlos Alberto Aquino Rodríguez}

La atracción para ir a Japón era tanta que una parte de los que se fueron no eran descendientes de japoneses. Algunos llegaron a comprar su adopción como descendiente de japonés, y otros falsificaron esta, y para parecerse nikkei llegaron incluso a operarse de los ojos.

De esta forma, el número de peruanos en 1990 aumentó a 10279 y en 1992 a 31 051. Sube el número y se ubica en 41317 en 1998, en 51772 en el 2002, en 58721 en el 2006 y 59723 el 20084, el máximo número que alcanzó (ver Gráfico 2). Al 1 de enero del 2009 había 3396 peruanos ilegales en ese país ${ }^{5}$. El número de ilegales ha decrecido en Japón pues la justicia se ha vuelto más estricta y la policía tiene más medios para actuar (aparte de que Japón es una isla, donde prácticamente todos entran por los aeropuertos y el control es mas fácil, y donde ser reconocido como extranjero es también fácil (en un país que es probablemente unos de los racialmente más homogéneos en el mundo, junto a Corea). Por otro lado, el número de peruanos deportados en los últimos años ha sido, en promedio, 500 .

En los últimos años el crecimiento del número de peruanos en Japón no ha sido por nuevos llegados sino prácticamente por el crecimiento vegetativo de la colonia peruana existente en el país, pues los nikkei en Perú que querían ir a Japón ya se han ido (casi la mitad de la comunidad nikkei ya se ha ido, según algunos cálculos).

Pero, de acuerdo a las estadísticas más actuales del Ministerio de Relaciones Exteriores del Perú, en diciembre del 2004 habían 68649 peruanos en Japón ${ }^{6}$, de los cuales 53649 en situación legal (y esta cifra es de una fuente japonesa, según lo señala el mismo Ministerio) y 15000 ilegales (pero esta cifra corresponde al número del año 1995 según fuente japonesa). La cifra de 53649 peruanos en situación legal del 2004 corresponde a la cifra japonesa de peruanos legales de un año antes, del año 2003. Según cifras japonesas en el año 2004 había 55750 peruanos legales en Japón y en 1 de enero del 2005 había 6624 ilegales, así que como se ve, la cifra japonesa es una cifra distinta de la que se calculo en el Perú.

4 Ver Ministry of Justice of Japan: "2009 Immigration Control", http://www.moj.go.jp/content/000007330. pdf

5 Según la fuente anterior. Un año antes habían 4481 ilegales y al 1 de enero del 2007 habían 5382 peruanos ilegales.

6 "Peruanos en el Exterior 2005 - Estadísticas", Ministerio de Relaciones Exteriores del Perú, http://www. rree.gob.pe/portal/aconsular.nsf/f7e99ca6ad554d4505256bff006da07a/16efe0852b45be8e0525712300 6e8560/\$FILE/ESTADISTICAS\%20PERUANOS\%20EN\%20EL\%20EXTERIOR.pdf 


\section{Pensamiento Crítico N. I3}

Gráfico 2. Cambio en el número de extranjeros registrados en Japón, por nacionalidad.

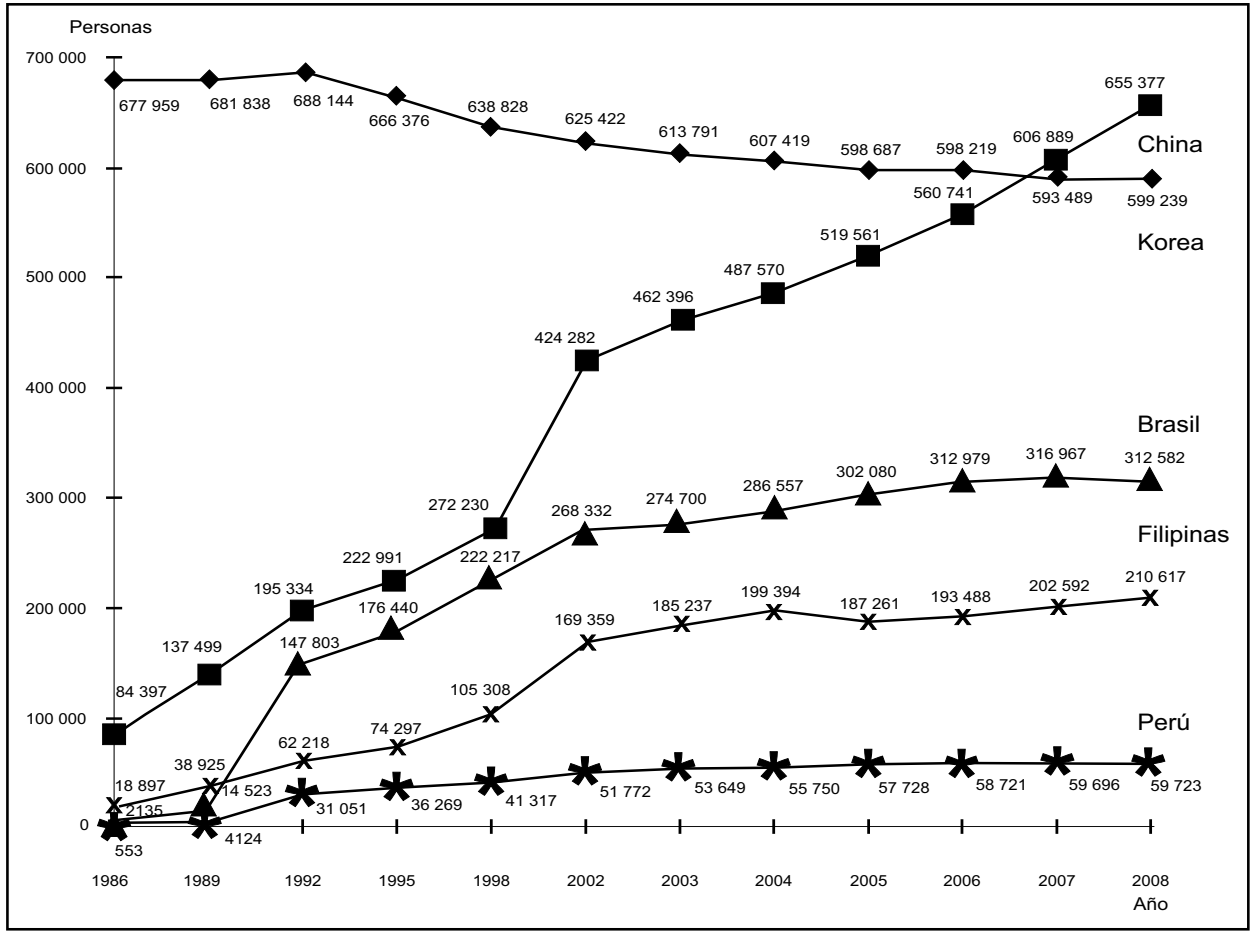

Fuente: Ministry of Justice of Japan: "2009 Immigration Control", http://www.moj.go.jp/content/000007330.pdf

Es necesario conocer el número exacto de peruanos en el exterior para saber cuántos hay en cada país y para que esto sirva, se debe establecer políticas para las comunidades peruanas afuera, pero al parecer esto no se ha llevado a cabo en forma exacta. En un estudio de la Organización Internacional para las Migraciones, OIM, se estimaba por ejemplo que el número total de peruanos que habían emigrado a Japón de 1990 al 2007, era de 71 987, cuando las estadísticas japonesas indicaban que al 2007 había 59696 peruanos (más 44981 ilegales). Ese número de peruanos en Japón según la OIM representaba el 3,7\% del 1940817 de peruanos que salieron al extranjero y no regresaron en ese mismo lapso 7 .

7 OIM: "Perú: Estadísticas de la Migración Internacional de Peruanos, 1990-2007", http://www1.inei.gob. pe/biblioineipub/bancopub/Est/Lib0758/Libro.pdf 


\section{Carlos Alberto Aquino Rodríguez}

Según un nuevo estudio, financiado en parte por la OIM y usando fuentes del Perú, se estima que el número de peruanos que fueron a Japón en el periodo 1990 a 2008 y que residen ahí es de 74 484, un 3.7\% del total de 2013090 de peruanos que salieron en ese mismo lapso ${ }^{8}$. Mientras tanto como vimos, a fines del 2008 había 59723 peruanos, más 3396 peruanos ilegales en el país nipón, según autoridades de ese país. En todo caso el problema con esos estudios realizados en el Perú es que no consultan fuentes de los países donde los peruanos residen. Una cosa es ver las estadísticas de peruanos que salen, que declaran ir a un país extranjero, pero otra cosa es ver cuánto de ellos se han quedado ahí y residen en ese país.

A modo de comparación, el número de peruanos en otros países de Asia es: en Corea en el 2004 había un estimado de 1100 peruanos, de los cuales 543 legales y 557 ilegales, en China había unos 202 en Beijing y 60 en Shangai, más unos 500 en Hong Kong, y en Taiwán había 27 peruanos, todo esto, según datos del Ministerio de Relaciones Exteriores del Perú del estudio anteriormente citado.

La reducción del número de peruanos en Japón en el último año se debe a que el gobierno de ese país dio incentivos en el 2009 para que los extranjeros se regresen a su país ante la crisis económica que atravesó, ya que tuvo una recesión en el 2008 y el 2009. En esos años la economía decreció $-1,2 \%$ y -5,2\% respectivamente. Se les financió el pasaje de regreso, dándoseles 300 mil yenes al titular y 200 mil yenes por dependiente, con el compromiso de que no podían regresar al país en los próximos tres años y que renuncien a su visa.

\section{Remesas de los peruanos en Japón y su situación actual}

Sobre las remesas que envían al país los peruanos en el extranjero, según estadísticas del Banco Central de Reserva del Perú, BCR, se recibió un total de 2444 millones de dólares el 2008 y 2378 millones de dólares en el 2009. Según esa fuente desde Japón se remesaron 227,29 millones de dólares en el 2008 y 190,24 millones de dólares en el 2009, el 9,3\% y el 8\% del total en esos años respectivamente. Japón es el tercer lugar desde donde se remesa más dinero al Perú, después de España que representa un $15,6 \%$ y el primero es EE.UU. con $40,8 \%$ del total en el 2009. Ver Cuadro 2. Esas cifras

8 Ver Aníbal Sánchez Aguilar: "Cambios Demográficos y Movilidad Laboral en la Región Asia Pacifico 2007-2008 Caso Perú”, OIM-UNFPA, agosto del 2010, Lima, Perú. Ver página 51.

9 "Memoria 2009", BCR. 


\section{Pensamiento Crítico N. 13}

son interesantes, pues en el 2008 las remesas de Japón representaron el 9,3\% del total, a pesar de que en ese país solo estaban el 3,7\% del total de peruanos que emigraron en los últimos 20 años.

Cuadro 2. Remesas del exterior, por países (en \%).

\begin{tabular}{|l|c|c|c|}
\hline & $\mathbf{2 0 0 7}$ & $\mathbf{2 0 0 8}$ & $\mathbf{2 0 0 9}$ \\
\hline Estados Unidos & 44,1 & 41,0 & 40,8 \\
\hline España & 15,1 & 15,3 & 15,6 \\
\hline Japón & 9,7 & 9,3 & 8,0 \\
\hline Italia & 6,0 & 6,2 & 6,7 \\
\hline Chile & 3,8 & 4,3 & 4,6 \\
\hline Argentina & 3,1 & 3,4 & 3,9 \\
\hline Resto de países 1/ & 18,2 & 20,4 & 20,4 \\
\hline Total & $\mathbf{1 0 0 , 0}$ & $\mathbf{1 0 0 , 0}$ & $\mathbf{1 0 0 , 0}$ \\
\hline
\end{tabular}

1 / incluye no clasificadas por países (medios informales).

Fuente: Superintendencia de Banca y Seguros (SBS), Bancos y empresas.

Memoria 2009, BCR.

Como se ve en el Gráfico 3, en los últimos años las remesas juegan un rol muy importante para los países en desarrollo, y el monto es cercano a lo que reciben por Inversión Extranjera Directa, IED, y es más que el monto de la Ayuda Económica que reciben. En el caso del Perú según cifras del BCR, las remesas de 2378 millones de dólares en el 2009 representaron el 1,9\% del PBI. 


\section{Carlos Alberto Aquino Rodríguez}

Gráfico 3. Flujos financieros a los países en desarrollo, 1990-2006. Remesas, IED y Ayuda Económica (miles de millones de dólares).

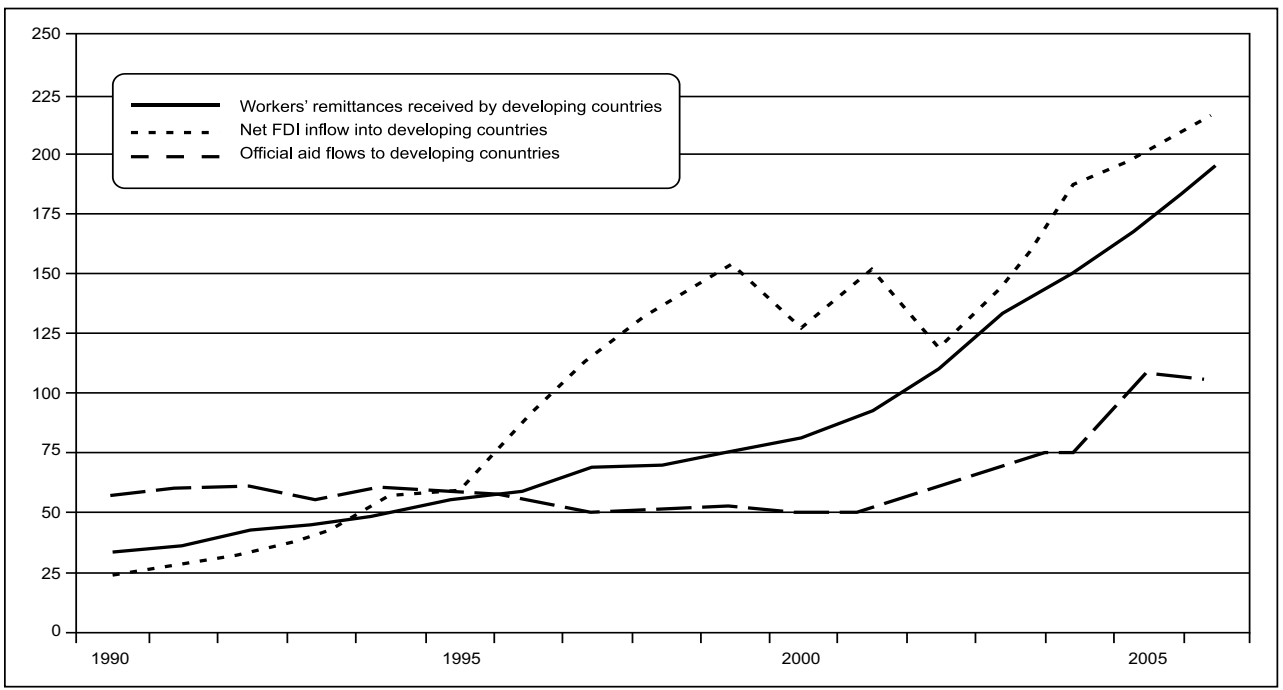

Fuente: WTO: "World Trade Report 2008", http://www.wto.org/english/res_e/booksp_e/anrep_e/wtr08-2b_e. pdf

Si hacemos historia vemos que la inmigración japonesa al Perú empezó en 1899, más de 20 años después que la inmigración china terminara. Esto último sucedió a raíz del famoso incidente del barco peruano "Maria Luz" que traía culíes chinos al Perú, y el gobierno chino prácticamente prohibió después la emigración de sus súbditos a nuestro país. ¿Qué había pasado? En julio de 1872 el barco peruano, estando acoderado en Yokohama, Japón, en su travesía al Perú, fue detenido por las autoridades japonesas y ordenado que su carga humana regrese a China, ante los maltratos que los culíes denunciaron sufrían. Desde 1849 hasta 1872 se calcula llegaron unos 100000 chinos a nuestro país. Ese incidente también posibilitó que el Perú estableciera relaciones diplomáticas con Japón en 1873 y con China el año siguiente ${ }^{10}$, las primeras de un país latinoamericano con esos países asiáticos.

10 Ver Carlos Aquino Rodríguez: "Relaciones Perú-Japón: Diplomacia, Inmigración, Economía y Política", 1994, Gráfica Biblos, Lima, Perú. 


\section{Pensamiento Crítico N. ${ }^{\circ}$ I3}

Se calcula que al Perú llegaron 33070 japoneses entre 1899 y 1941. Después ya no llegaron más por el clima antijapones en el país, y en 1942 el gobierno peruano declara la guerra a Japón, confisca los bienes de los japoneses y deporta hacia campos de concentración, en EE.UU., a 1771 miembros de la colonia japonesa.

Noventa años después de la llegada de los primeros japoneses al Perú, sus descendientes empezaron una migración masiva al país de sus antepasados. Así, la migración de nikkei a Japón, que empezó a fines de la década de 1980, ha hecho que ahora casi la mitad de ellos estén en ese país.

En el Tratado de Libre Comercio, o más exactamente el AAE, el Acuerdo de Asociación Económica que Perú negoció con Japón y que concluyó en noviembre del 2010, se trató solo parcialmente el tema de la migración laboral de peruanos en ese país. Japón ha negociado el movimiento de personas, como de enfermeras, cocineros, masajistas, en los acuerdos que ha firmando con Tailandia, Filipinas e Indonesia por ejemplo.

Del sistema anterior, para admitir enfermeras de esos países, para que trabajen en Japón, se sigue el procedimiento siguiente: los candidatos tienen que tener el título de enfermeros/as de su país y tener experiencia en este campo, al ingresar a Japón reciben seis meses de enseñanza en idioma japonés, después reciben entrenamiento y practican en un centro de salud, y luego en los tres años que tienen de estadía deben pasar un examen nacional para ser calificados para trabajar como enfermeros/as. Este examen se da una vez al año; si no pasan este examen, se tienen que regresar a su país.

Este sistema ha recibido críticas pues desde que empezó en el año fiscal japonés 2008 (de abril a marzo), ha habido ya dos exámenes anuales y el número de aprobados se cuentan con los dedos de la mano. En el primero nadie aprobó y en el segundo examen, tomado en febrero del 2010, solo pasaron tres (un filipino y dos indonesios), de un total de 254 postulantes de Indonesia y Filipinas, es decir pasaron solo el 1\% del total, mientras que los postulantes japoneses tuvieron un porcentaje de aprobación del $90 \%$. El problema es que el examen es en japonés. Esos postulantes extranjeros tienen solo una última oportunidad con el examen del 2011. Si no pasan se regresaran a su país y fracasaría el intento japonés de traer enfermeras extranjeras. Para evitar que esto suceda el gobierno ha decidido simplificar algunos kanjis (ideogramas chinos) que usan 


\section{Carlos Alberto Aquino Rodríguez}

en su escritura para el examen, y poner el nombre de las enfermedades en su nombre médico también, para hacer de esa forma más fácil el examen para los extranjeros ${ }^{11} \mathrm{y}$ finalmente se decidió poner en idioma ingles los kanjis mas difíciles ${ }^{12}$.

Japón de todas maneras necesitará mano de obra, pues desde el 2005 su población decrece en número. Se estima que su población actual, de 127,5 millones será un $25 \%$ menor en el 2050, alcanzando los 95 millones. Además, actualmente un 23\% de los japoneses ya son mayores de 65 años y en el 2050 esta proporción subirá al 40\% del total de su población.

Pero Japón no recibe inmigrantes tan fácilmente como otros países. Es un país bastante homogéneo racialmente, donde los extranjeros solo eran el 1,74\% de la población total a fines del 2008 (y la mayoría de ellos chinos y coreanos, ver Gráficos 1 y 3).

Gráfico 4. Número de extranjeros en Japón y como \% de la población total.

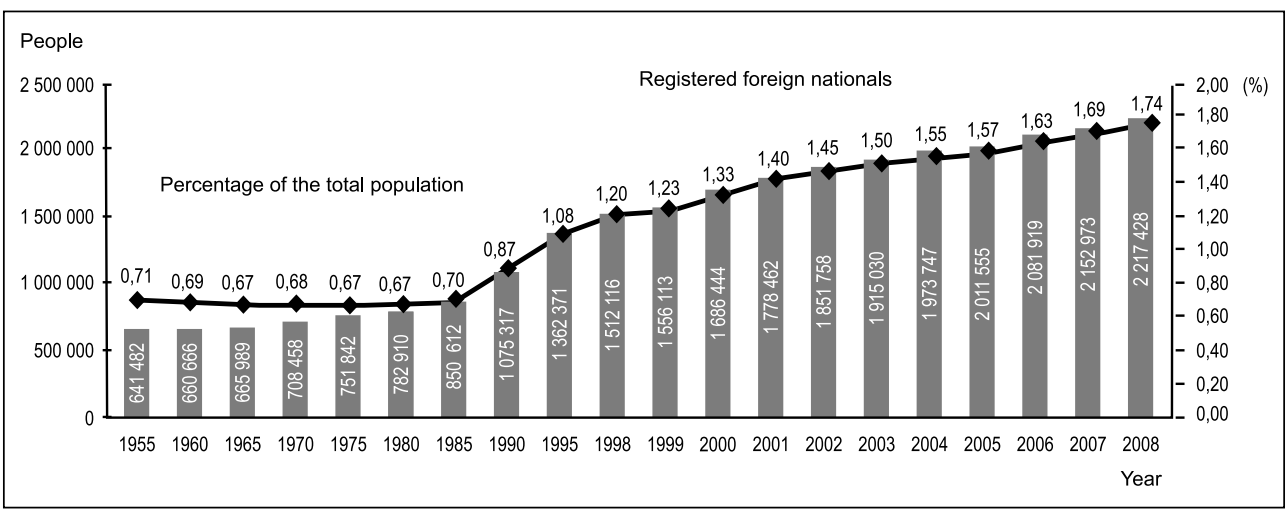

Fuente: Ministry of Justice of Japan: "2009 Immigration Control”, http://www.moj.go.jp/content/000007330.pdf

Al no haber ya más nikkei que puedan ir a Japón a trabajar, la otra forma de que peruanos vayan a Japón será a través de un sistema que los japoneses crearon hace algunos años, el de entrenamiento y practicante laboral por un número determinado de años (3 años). Este sistema lo maneja el JITCO o Japan International Training

11 Ver Asahi Shinbun online: "Kangoshi shiken, byomei ni eigo heiki he, EPA no Gaikokujin futan keigen", http://www.asahi.com/national/update/0824/TKY201008240253_01.html

12 Ver Internacional Press: "Japón facilita examen para enfermeros extranjeras", http://www.ipcdigital.com/ es/Noticias/Sociedad/Japon-facilita-examen-para-enfermeros-extranjeros-_15-diciembre-2010 


\section{Pensamiento Crítico N. ${ }^{\circ} 3$}

Cooperation Organization. Creado en 1991, trae a Japón trabajadores del extranjero para hacer un entrenamiento técnico, que les posibilite la oportunidad laboral en empresas japonesas en variados campos.

A través del programa que maneja JITCO miles de extranjeros han estado en Japón. El Perú también ha enviado hasta ahora a algunas decenas de ellos. Pero en el 2010 el gobierno peruano, a través del Ministerio de Trabajo y Promoción del Empleo, firmó un acuerdo con JITCO para poder enviar en forma regular en el futuro a más peruanos (un primer acuerdo se había firmado ya en 1994). En abril del 2010 se llevó a cabo la reunión para formalizar el envió de más trabajadores peruanos, dado que en julio de ese año se introducían cambios en la Ley de Migraciones en Japón para el tratamiento de extranjeros que van a trabajar bajo el sistema de $\mathrm{JITCO}^{13}$. De llevarse a cabo este sistema en el Perú, sería algo interesante pues los trabajadores que irían tendrían las mismas condiciones laborales de sus pares japoneses (además que recibirían, antes de irse a Japón, un breve curso de idioma y cultura japonesa para adaptarse mejor a ese país, que es diferente del Perú en muchos aspectos).

Con algunos peruanos regresando de Japón, y pensando en la contribución que estos pueden hacer al desarrollo económico del país, se estima que ellos podrían participar con los conocimientos que han adquirido en el país nipón y aplicarlos aquí. Incluso el BID, a través del Fondo Multilateral de Inversiones, FOMIN, creó un programa en el 2004 para capacitar a los peruanos que regresan para que hagan negocios en el Perú ${ }^{14}$, incluso dándoles algún préstamo para que inicien un negocio, pero este programa no funcionó tal como se planteo inicialmente.

Los peruanos que se quedan allá, que son la mayoría de ellos, pueden contribuir difundiendo lo peruano, y por ejemplo ayudar así a la introducción de productos del Perú a ese país ${ }^{15}$. Se habla por ejemplo de la comida, que con los restaurantes peruanos establecidos en Japón podrían ayudar a difundir más nuestro sabor nacional entre los japoneses y a colocar productos relacionados en ese país.

13 Ver "Annual Meeting: Contact Officials from the Government of Peru", http://www.jitco.or.jp/english/ engagement_sending_out/peru/2010/

14 Banco Interamericano de Desarrollo "Apoyo a los Empresarios que retornan al país", http://www.iadb.org/ projects/Project.cfm?project $=$ PE-M1006\&Language $=$ Spanish

15 Ver Carlos Aquino Rodríguez: "Migración de Peruanos a Japón y Oportunidades de Negocios", en Revista Calidad y Creatividad, Facultad de Ciencias Económicas y Empresariales, Universidad Ricardo Palma, N. ${ }^{\circ}$ Julio 2006. 


\section{Carlos Alberto Aquino Rodríguez}

Por último, los peruanos en Japón, que tradicionalmente trabajaban en su mayoría en fábricas que producían para la exportación, ya no lo están haciendo en ese sector ante el alza del yen que resta competitividad internacional a los productos japoneses. El panorama en estos momentos no es alentador, pues hay también el problema de la deflación, al estar los precios en caída esto hará que la recuperación económica de la recesion del 2008 y 2009 sea bastante lenta. Incluso algunos temen que podría repetirse ahora el panorama de una década perdida más, pues como se recuerda en la década de 1990 y la década pasada el crecimiento económico promedio anual fue de $1,4 \%$ y $0,7 \%$ respectivamente en Japón. A esas dos décadas los japoneses los llaman las décadas perdidas ${ }^{16}$.

\section{Conclusiones}

En todo caso el tema de la migración de peruanos en Japón es un aspecto particular de un tema más general: los peruanos que están fuera del país. Se calcula que más del $10 \%$ de la población peruana esta en el extranjero. Se necesita políticas para afrontar esta realidad, como las siguientes:

1. Es necesario conocer más exactamente cuántos peruanos están afuera. Tarea nada fácil pues se calcula que la mitad están de ilegales en muchos de esos países. Hay que utilizar más datos de fuentes de esos países para saber cuántos peruanos están ahí (como en el caso de Japón aquí expuesto).

2. Las autoridades peruanas deben establecer mecanismos para que los peruanos que vayan a trabajar afuera cuenten con las condiciones para hacerlo en forma digna y con los mecanismos de protección legal. Un paso en este sentido es el establecimiento de convenios de envío de trabajadores con contrato, como el que se tiene con España para determinados trabajos y el que se piensa implementar con Japón. Por otro lado, algunos países tiene una agencia dedicada especialmente a establecer convenios con países para el envío de sus trabajadores, como es el caso de Filipinas con su Philippine Overseas Employment Administration (POEA) ${ }^{17}$. Este país desde hace 38 años monitorea y administra a sus trabajadores en el extranjero.

16 Ver Carlos Aquino Rodríguez “¿Puede ser Japón otra Grecia?: El peso de la deuda publica y los problemas de la economía japonesa", Página Web de la Facultad de Ciencias Económicas, UNMSM (lado derecho, Sección Artículos y Noticias), http://economia.unmsm.edu.pe/Noticias/JapoGrecia_19.07.10.pdf

17 Ver la experiencia de esta institución en Dovelyn Rannveig Agunias: "Managing Temporary Migration: Lessons from the Philippine Model”, http://www.migrationpolicy.org/pubs/Insight_POEA_Oct07.pdf 


\section{Pensamiento Crítico N. 13}

El POEA se creó en 1982 unificando a varias agencias que ya existían. Se estima que la mitad de filipinos que trabajan, lo hacen bajo esos convenios.

3. Establecer en los Tratados de Libre Comercio que el Perú negocia, mecanismos de movilidad laboral como el que Japón por ejemplo ha establecido con algunos países asiáticos. El Perú ha terminado negociaciones con Japón y Corea, y tiene en agenda negociar otros más con Australia, Nueva Zelanda, Sudáfrica, India y Rusia, entre otros.

4. Establecer mecanismos para que los peruanos que regresen al país puedan aportar con sus conocimientos al desarrollo del país.

5. Las remesas han cumplido unos roles muy importantes: primero, sostener a las familias de los que emigraron y, segundo, dinamizar la economía del país. De hecho algunos países, como Bangladesh, Haití, viven de las remesas. Pero sería interesante ver mecanismos para que ese dinero se use de forma tal que no sirva para perpetuar la migración de peruanos hacia afuera. Por ejemplo, el dinero se usaría en parte para financiar el estudio en profesiones que no es fácil encontrar empleo y que eviten la migración de personas.

\section{Bibliografía}

Aníbal Sánchez Aguilar: "Cambios Demográficos y Movilidad Laboral en la Región Asia Pacifico 2007-2008 Caso Perú", OIM-UNFPA, Agosto del 2010, Lima, Perú.

Banco Interamericano de Desarrollo "Apoyo a los Empresarios que retornan al país", http://www.iadb.org/projects/Project.cfm?project=PE-M1006\&Language $=$ Spanish

Carlos Aquino Rodríguez: "Migración de Peruanos a Japón y Oportunidades de Negocios", en Revista Calidad y Creatividad, Facultad de Ciencias Económicas y Empresariales, Universidad Ricardo Palma, Julio 2006.

Carlos Aquino Rodríguez "¿Puede ser Japón otra Grecia?: El peso de la deuda pública y los problemas de la economía japonesa", Pagina Web de la Facultad de Ciencias Económicas, UNMSM (lado derecho, Sección Artículos y Noticias), http://economia. unmsm.edu.pe/Noticias/JapoGrecia_19.07.10.pdf 


\section{Carlos Alberto Aquino Rodríguez}

Carlos Aquino Rodríguez: "Relaciones Perú-Japón: Diplomacia, Inmigración, Economía y Política”, 1994, Grafica Biblos, Lima, Perú.

Dovelyn Rannveig Agunias: "Managing Temporary Migration: Lessons from the Philippine Model”, http://www.migrationpolicy.org/pubs/Insight_POEA_Oct07.pdf

Ministerio de Relaciones Exteriores del Perú: "Peruanos en el Exterior 2005 Estadísticas", http://www.rree.gob.pe/portal/aconsular.nsf/f7e99ca6ad554d450525 6bff006da07a/16efe0852b45be8e05257123006e8560/\$FILE/ESTADISTICAS\%20 PERUANOS\%20EN\%20EL\%20EXTERIOR.pdf

Ministry of Justice of Japan: "2009 Immigration Control", http:/www.moj.go.jp/ content/000007330.pdf

OIM: "Perú: Estadísticas de la Migración Internacional de Peruanos, 1990-2007", http:// www1.inei.gob.pe/biblioineipub/bancopub/Est/Lib0758/Libro.pdf 